\title{
Prevalence of carbapenemase-producing Klebsiella pneumoniae at a tertiary care hospital in Kathmandu, Nepal
}

Susil Pyakurel ${ }^{1 *}$ (D, Mehraj Ansari ${ }^{1}$, Smriti Kattel ${ }^{1}$, Ganesh Rai ${ }^{1}$, Prasha Shrestha', Kul Raj Rai ${ }^{1,2}$, Anil Kumar Sah ${ }^{3}$ and Shiba Kumar Rai ${ }^{1,4}$

\begin{abstract}
Aim: Although carbapenem is the last-resort drug for treating drug-resistant Gram-negative bacterial infections, prevalence of carbapenem-resistant bacteria has substantially increased worldwide owing to irrational use of antibiotics particularly in developing countries like Nepal. Therefore, this study was aimed to determine the prevalence of carbapenemase-producing K. pneumoniae and to detect the carbapenemase genes (blaNDM-2 and blaOXA-48) in at a tertiary care hospital in Nepal.

Materials and methods: A hospital-based cross-sectional study was carried out from June 2018 to January 2019 at the Microbiology Laboratory of Annapurna Neurological Institute and Allied Sciences, Kathmandu, Nepal. Different clinical samples were collected and cultured in appropriate growth media. Biochemical tests were performed for the identification of K. pneumoniae. Antibiotic susceptibility testing (AST) was performed by the Kirby-Bauer disc diffusion method. The modified Hodge test (MHT) was performed to detect carbapenemase producers. The plasmid was extracted by the modified alkaline hydrolysis method. Carbapenemase-producing K. pneumoniae were further confirmed by detecting blaNDM-2 and blaOXA-48 genes by PCR using specific forward and reverse primers followed by gel electrophoresis.
\end{abstract}

Results: Out of the total 720 samples, 38.9\% (280/720) were culture positive. K. pneumoniae was the most predominant isolate $31.4 \%$ (88/280). Of $88 \mathrm{~K}$. pneumoniae isolates, 56.8\% (50/88) were multi-drug resistant (MDR), and 51.1\% (45/88) were MHT positive. Colistin showed the highest sensitivity (100\%; 88/88), followed by tigecycline (86.4\%; 76/88). blaNDM-2 and blaOXA-48 genes were detected in 24.4\% (11/45) and 15.5\% (7/45) of carbapenemase-producing K. pneumoniae isolates, respectively.

Conclusion: The rate of MDR and carbapenemase production was high in the K. pneumoniae isolates. Colistin and tigecycline could be the drug of choice for the empirical treatments of MDR and carbapenemase-producing K. pneumoniae. Our study provides a better understanding of antibiotic resistance threat and enables physicians to select the most appropriate antibiotics.

Keywords: Carbapenemase, MDR, Colistin, MHT, Nepal

*Correspondence: suseel51@gmail.com

1 Department of Microbiology, Shi-Gan International College of Science and Technology, Kathmandu, Nepal

Full list of author information is available at the end of the article

\section{Introduction}

Klebsiella pneumoniae is an opportunistic Gram-negative bacterium responsible for several of nosocomial infections including urinary tract infections, pneumonia, and septicemia [1]. It is one of the most frequently original author(s) and the source, provide a link to the Creative Commons licence, and indicate if changes were made. The images or other third party material in this article are included in the article's Creative Commons licence, unless indicated otherwise in a credit line to the material. If material is not included in the article's Creative Commons licence and your intended use is not permitted by statutory regulation or exceeds the permitted use, you will need to obtain permission directly from the copyright holder. To view a copy of this licence, visit http://creativecommons.org/licenses/by/4.0/. 
isolated organisms after Escherichia coli from clinical specimens in Nepal [2] and has a greater clinical significance. Irrational and widespread use of antimicrobial agents has led to the increase in antimicrobial resistance in these isolates [3] and the multidrug-resistant (MDR) $K$. pneumoniae isolates have been reported by many workers in Nepal $[2,4,5]$. Such multidrug-resistant $K$. pneumoniae isolates show a high resistance to a broad spectrum of drugs including beta-lactam antibiotics, fluoroquinolones, and aminoglycosides [6]. Until now, carbapenems were considered as the most effective drug against the MDR K. pneumoniae and frequently used as the drugs of last resort [7]. However, the overdependence on carbapenems has led to an undesirable increase in the carbapenem-resistant isolates [8].

Carbapenem resistance is mediated by the production of carbapenemases; $\beta$-lactamases with versatile hydrolytic capacities or by the combination of outer membrane porin expression disruption [1]. Different carbapenemase genes are responsible for the production of carbapenemases, the most clinically significant carbapenemases are class A (KPC type), class B metallo- $\beta$-lactamases (MBLs), i.e., VIM, IMP, and NDM types, and class D carbapenemhydrolyzing $\beta$-lactamases (OXA-48-like enzymes) [9, 10]. The New Delhi metallo- $\beta$-lactamases (NDM), first reported in India [11] and OXA-48, first reported in Turkey [12] and both have been reported in K. pneumoniae. Since their first detection, both of the carbapenemase genes have spread across the globe [11-14]. Frequent isolation of the carbapenemase-producing isolates poses a significant complication in the treatment. Furthermore, these genes have the potential for dissemination via mobile genetic elements such as plasmids and transposons [15] which increases the risk of widespread dissemination in hospital settings as well as in the community.

In Nepal, the prevalence of carbapenemase-producing $K$. pneumoniae have been reported by several workers [16, 17]; however, data obtained by most of previous studies were mainly based on phenotypic characterization of carbapenemase-producing $K$. pneumoniae, but not by molecular methods [16]. Recently, a few authors have reported the prevalence of blaOXA- 48 genes in $K$. pneumoniae ranging from nearly 10 to $70 \%$ [16-18]. On the other hand, the NDM series of genes of Indian origin could have been easily circulating in Nepal $[16,19]$ owing to the Indo-Nepal open border facilitating people to move freely between the two countries. In this study, we therefore, wanted to address this pressing need by detecting the blaNDM- 2 and blaOXA-48 genes among the carbapenemase-producing $K$. pneumoniae at a tertiary care center in Nepal. This study helps to determine the prevalence of blaOXA-48 blaNDM-2-producing $K$. pneumoniae and to design apt antibiotic prescription in days to come.

\section{Materials and methods Study design}

This cross-sectional study was conducted from June 2018 to January 2019 at Annapurna Neurological Institute and Allied Sciences, Kathmandu, Nepal. The hospital is a 200-bed referral hospital located in the middle of Kathmandu. The hospital provides services for patients of the Kathmandu valley and also, patients referred from other hospitals outside the Kathmandu valley. The study population included patients of all ages and genders visiting the both outpatient and inpatient department of the hospital. The patients under any antimicrobial treatments were excluded from the study.

\section{Sample collection and identification}

The samples included were urine, blood, sputum, CSF, pus, tracheal aspirates and catheter tips. Samples were collected by employing standard microbiological protocol [20]. Repeated samples and samples showing the possible signs of contaminations were excluded from this study. Valid specimens were cultured in suitable culture media as per their requirements. Identification of $K$. pneumoniae was made based on colonial morphology, staining reactions, and various biochemical properties [21].

\section{Antimicrobial susceptibility testing (AST)}

The identified $K$. pneumoniae isolates were subjected to an in vitro antimicrobial susceptibility testing by the modified Kirby-Bauer disc diffusion method as recommended by CLSI guidelines [22]. The antibiotic disks used were ampicillin $(10 \mu \mathrm{g})$, gentamicin $(10 \mu \mathrm{g})$, ciprofloxacin $(5 \mu \mathrm{g})$, co-trimoxazole $(25 \mu \mathrm{g})$, amikacin $(30 \mu \mathrm{g})$, ceftazidime $(30 \mu \mathrm{g})$, cefotaxime $(30 \mu \mathrm{g})$, imipenem $(10 \mu \mathrm{g})$, meropenem $(10 \mu \mathrm{g})$, ertapenem $(10 \mu \mathrm{g})$, tigecycline $(15 \mu \mathrm{g}$ and colistin $(10 \mu \mathrm{g}) . \mathrm{K}$. pneumoniae which were resistant to at least 3 different classes of antibiotics were considered as multidrug-resistant strains.

\section{Screening of carbapenemase producers}

Imipenem, meropenem, and ertapenem discs were incorporated in the primary AST plate for the screening of the carbapenemase producers. Isolates showing resistance to at least one of the carbapenem discs mentioned were suspected as possible carbapenemase producers and were processed for a further confirmatory test.

\section{Confirmation of carbapenemase production}

Carbapenemase production was confirmed phenotypically by the Modified Hodge Test (MHT). For this, an 
overnight suspension of E. coli (ATCC 25922) adjusted to a turbidity of the $0.5 \mathrm{McF}$ arland standard was inoculated evenly on the surface of the MHA plate containing $70 \mu \mathrm{g}$ per $\mathrm{ml}$ of $\mathrm{ZnSO}_{4}$. After drying at room temperature, meropenem was placed at the center of the plate, and then the screening positive isolates were stroked from the edge of the disk to the periphery of the plate and incubated overnight at $37^{\circ} \mathrm{C}$ aerobically. The presence of a clover leaf-shaped inhibition zone was considered carbapenemase production. The confirmed isolates were preserved in $25 \%$ glycerol and stored at $-20{ }^{\circ} \mathrm{C}$ until further confirmation by molecular test.

\section{Molecular characterization of blaOXA-48- and blaNDM-2-producing K. pneumoniae}

DNA (plasmid) was extracted by the modified alkaline hydrolysis method [23]. The DNA extracts were resuspended in Tris-EDTA (10 mM Tris-HCL, $0.10 \mathrm{mM}$ EDTA, $\mathrm{pH}$ 8.0) buffer and stored at $4{ }^{\circ} \mathrm{C}$ for further analysis. The DNA extracts were amplified by PCR (Proflex, Thermo Fisher, USA) as described by Dallence et al. [24] for blaOXA-48 genes and Kaase et al. [25] for blaNDM-2 genes. The primers used were: OXA48 F-GCTTGATCGCCCTCGATT, OXA-48 R-GAT TTGCTCCGTGGCCGAAA for blaOXA-48 genes and NDM-2 F CACCTCATGTTTGAATTCGCC, NDM-2
R CTCTGTCACATCGAAATCGC manufactured by Macrogen (Korea). For gene amplification, $4 \mu \mathrm{l}$ plasmid DNA, $12.5 \mu \mathrm{l}$ master mix manufactured by Solis Biodyne Company, Estonia, $7.5 \mu \mathrm{l}$ nuclease-free water, and $0.5 \mu \mathrm{l}$ each of reverse and forward primers were added to make a final mixture volume of $25 \mu$ l. The optimized conditions for the thermal cycling process was initial denaturation at $94{ }^{\circ} \mathrm{C}$ for $10 \mathrm{~min}$, denaturation at $94{ }^{\circ} \mathrm{C}$ for $40 \mathrm{~s}$, annealing at $60{ }^{\circ} \mathrm{C}$ for $40 \mathrm{~s}$, and extension at $72{ }^{\circ} \mathrm{C}$ for $1 \mathrm{~min}$ with a final extension at $72{ }^{\circ} \mathrm{C}$ for $7 \mathrm{~min}$ at the end of 30 cycles, followed by maintenance at $4{ }^{\circ} \mathrm{C}$ for OXA-48 and initial denaturation at $94{ }^{\circ} \mathrm{C}$ for $3 \mathrm{~min}$, denaturation at $94{ }^{\circ} \mathrm{C}$ for $50 \mathrm{~s}$, annealing at $54{ }^{\circ} \mathrm{C}$ for $50 \mathrm{~s}$ and extension at $72{ }^{\circ} \mathrm{C}$ for $50 \mathrm{~s}$ with a final extension at $72{ }^{\circ} \mathrm{C}$ for $5 \mathrm{~min}$ at the end of 35 cycles, followed by maintenance at $4{ }^{\circ} \mathrm{C}$ for NDM-2. Ethanol precipitation method was used to purify the amplified DNA [26].

Electrophoresis of the amplified DNA was performed in $1.5 \%$ agarose gel stained with $0.5 \mu \mathrm{l}$ ethidium bromide. Finally, the gel was visualized under a UV trans-illuminator for photo-documentation. The molecular weight of the amplified product was estimated using a 1000-bp plus DNA ladder (Solis Biodyne, Estonia). The band of $281 \mathrm{bp}$ and 984 bp were considered positive for the blaOXA-48 and blaNDM-2genes, respectively [24, 25].

Antibiotic sensitivity patterns of $K$. pneumoniae isolates $(\mathrm{n}=88)$

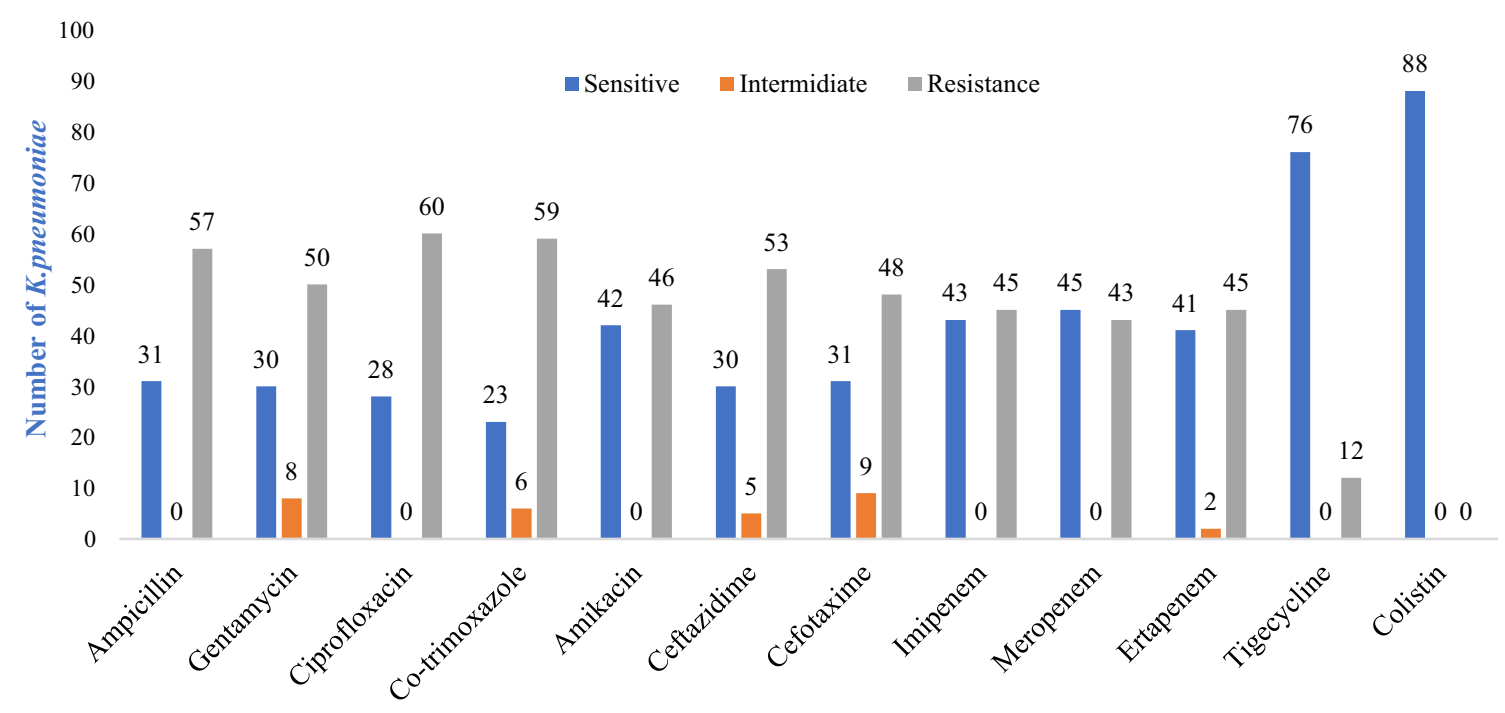

Antibiotics used

Fig. 1 Antibiotic sensitivity patterns of K. pneumoniae isolates $(n=88)$ 


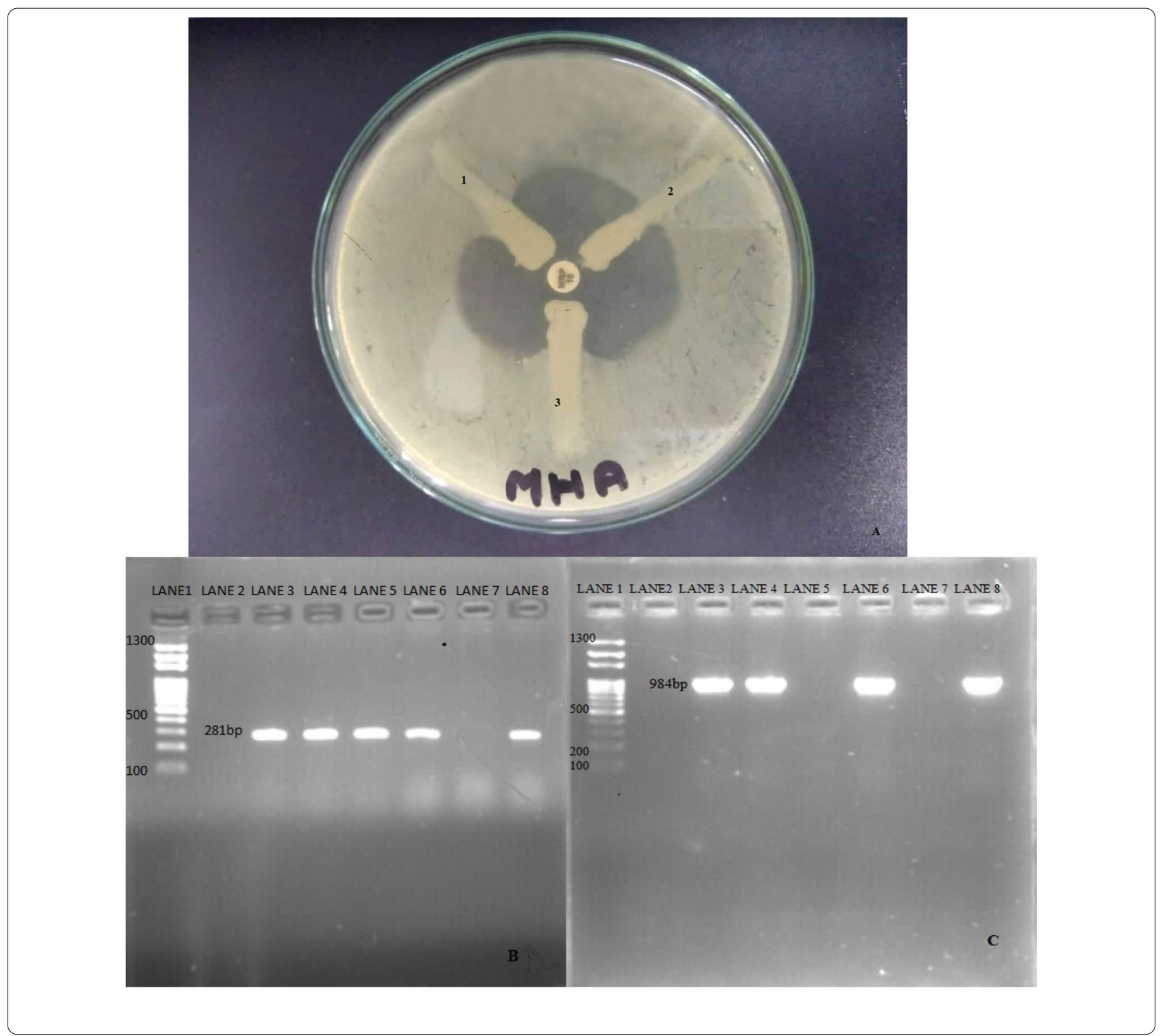

Photograph A: Modified Hodge test (MHT): A-negative control, B-positive control and C- test organism (positive). Photograph B: Gel electrophoresis of PCR amplicon of blaOXA-48 gene (281 bp) (lane 1 ladder, lane 2 negative control, lane 3 positive control, lanes 4,5 , 6 \& 8 positive samples and lane 7 negative sample). Photograph C: Gel electrophoresis of PCR amplicon of blaNDM-2 gene (984 bp) (lane 1 ladder, lane 2 negative control, lane 3 positive control, lanes $4,6 \& 8$ positive samples and lanes 5 \& 7 negative samples)

\section{Quality control}

All the tests were carried out by following standard aseptic techniques and CLSI guidelines [20, 22]. K. pneumoniae (ATCC 700603) was used to ensure the performance of newly prepared media and the quality control of AST and MHT. During PCR, quality control was assured by $K$. pneumoniae (ATCC 700603) isolates carrying both the genes under question.

\section{Statistical analysis}

Statistical analysis was performed using Statistical Package for Social Science (SPSS) version 16. Chi-square test at $95 \%$ confidence interval (CI) was performed to evaluate the association between demographic variables.

\section{Results}

\section{Growth positivity}

Among the 720 samples collected, 38.9\% (280/720) were found culture positive. Of the culture-positive 
Table 1 Growth positivity according to sex, clinical samples, and hospital units

\begin{tabular}{|c|c|c|c|c|}
\hline & $\begin{array}{l}\text { Growth positive } \\
n(\%)\end{array}$ & $\begin{array}{l}\text { Gram negative } \\
(\%)^{*}\end{array}$ & $\begin{array}{l}\text { K. pneumoniae } \\
(\%)^{*}\end{array}$ & $\begin{array}{l}\text { MDR K. pneumoniae } \\
(\%)^{* *}\end{array}$ \\
\hline \multicolumn{5}{|l|}{ Sex } \\
\hline Male $(n=392)$ & $144(36.7 \%)$ & $68(47.2 \%)$ & $37(25.7 \%)$ & $23(62.2 \%)$ \\
\hline Female $(n=328)$ & $136(41.5 \%)$ & $86(63.2 \%)$ & $51(37.5 \%)$ & $27(52.9 \%)$ \\
\hline \multicolumn{5}{|l|}{ Sample } \\
\hline Urine $(n=272)$ & $110(40.4 \%)$ & $63(57.2 \%)$ & $24(21.8)$ & $11(45.8 \%)$ \\
\hline Sputum $(n=127)$ & $58(45.7 \%)$ & $31(53.4 \%)$ & $23(39.7 \%)$ & $16(69.6 \%)$ \\
\hline Catheter tips $(n=89)$ & $32(35.9 \%)$ & $23(71.9 \%)$ & $14(43.8 \%)$ & $8(57.1 \%)$ \\
\hline Tracheal aspirates $(n=87)$ & $42(48.3 \%)$ & $24(57.1 \%)$ & $21(50.0 \%)$ & $12(57.1 \%)$ \\
\hline Others $^{\#}(n=145)$ & 38 (26.2\%) & $13(34.2 \%)$ & $6(15.8 \%)$ & $3(50.0 \%)$ \\
\hline \multicolumn{5}{|l|}{ Hospital units } \\
\hline $\mathrm{OPD}(n=280)$ & $118(42.1 \%)$ & $79(66.9 \%)$ & $41(34.7 \%)$ & $24(58.5 \%)$ \\
\hline General ward $(n=262)$ & $64(24.4 \%)$ & $31(48.4 \%)$ & $27(42.1 \%)$ & $11(40.7 \%)$ \\
\hline $\operatorname{ICU}(n=178)$ & $98(55.0 \%)$ & $44(44.9 \%)$ & $20(20.4 \%)$ & $15(75.0 \%)$ \\
\hline Total (720) & $280(38.8 \%)$ & $154(55.1 \%)$ & $88(31.4 \%)$ & $50(56.8 \%)$ \\
\hline
\end{tabular}

MDR multi drug resistant, ICU intensive care unit, OPD out-patient department; others ${ }^{\#}$ denotes throat swab, vaginal swab, synovial fluid, and pleural fluid, blood; *denotes percentage was calculated on growth positive, and ${ }^{* *}$ denotes percentage was calculated on $K$. pneumoniae isolates

samples, 55.0\% (154/280) were Gram-negative, and 45.0\% (126/280) were Gram-positive. K. pneumoniae, 31.4\% $(88 / 280)$ was the most predominant isolate. Females had a higher isolation rate than males. Tracheal aspirates had the highest $48.3 \%(42 / 87)$ culture positivity followed by sputum $45.7 \%$ (58/127), urine $40.4 \%$ (110/272), catheter tips $35.9 \%$ (32/89), and others. Among the wards, the highest culture positivity was obtained in the ICU $55.1 \%$ (98/178), followed by the OPD $42.2 \%(118 / 280)$ and general ward 24.4\% (64/262); however, the isolation rate of $K$. pneumoniae was the highest $42.1 \%(27 / 64)$ in the general ward and the least in the ICU (Table 1).

\section{Antibiotic susceptibility testing}

Among the 12 different antibiotics used against $K$. pneumoniae, colistin was found to be the most effective (100\% sensitive), followed by tigecycline $(86.3 \%$ sensitive; 76/88), whereas co-trimoxazole was the least effective (26.1\% sensitive; 23/88). Maximum sensitivity and resistivity to most of the antibiotics were found

Table 2 Distribution of MDR, MHT-positive and blaNDM-2 and blaOXA-48 genes-harboring K. pneumoniae

\begin{tabular}{|c|c|c|c|c|c|}
\hline K. pneumoniae count $(N)$ & $\begin{array}{l}\text { Carbapenem resistant } \\
(\%)^{*}\end{array}$ & $\begin{array}{l}\text { MHT positive } \\
(\%)^{*}\end{array}$ & $p$-value & $\begin{array}{l}\text { blaOXA-48 } \\
(\%)^{* *}\end{array}$ & $\begin{array}{l}\text { blaNDM-2 } \\
(\%)^{* *}\end{array}$ \\
\hline \multicolumn{6}{|l|}{ Sex } \\
\hline Male $(n=37)$ & $26(70.3 \%)$ & $23(62.2 \%)$ & 0.07 & $4(17.4 \%)$ & $6(26.1 \%)$ \\
\hline Female $(n=51)$ & $32(62.7 \%)$ & $22(43.1 \%)$ & & $3(13.6 \%)$ & $5(22.7 \%)$ \\
\hline \multicolumn{6}{|l|}{ Clinical samples } \\
\hline Urine $(n=24)$ & $13(54.1 \%)$ & $12(50 \%)$ & 0.367 & $2(16.7 \%)$ & $5(41.7 \%)$ \\
\hline Sputum $(n=23)$ & $18(78.2 \%)$ & $10(43.5 \%)$ & & $1(10 \%)$ & $2(20.0 \%)$ \\
\hline Catheter tips $(n=14)$ & 9 (64.3\%) & 7 (50.0\%) & & $1(14.3 \%)$ & $1(14.3 \%)$ \\
\hline Tracheal aspirates $(n=21)$ & $16(76.2 \%)$ & 15 (71.4\%) & & $2(13.3 \%)$ & $3(20.0 \%)$ \\
\hline Others $(n=6)$ & $2(33.3 \%)$ & $1(16.7 \%)$ & & $0(0.0 \%)$ & $0(0.0 \%)$ \\
\hline \multicolumn{6}{|l|}{ Hospital units } \\
\hline $\mathrm{OPD}(n=41)$ & $24(65.9 \%)$ & $19(46.3 \%)$ & 0.627 & $3(15.8 \%)$ & $3(15.8 \%)$ \\
\hline General ward $(n=27)$ & $16(59.3 \%)$ & $13(48.1 \%)$ & & $1(7.7 \%)$ & $2(15.4 \%)$ \\
\hline $\mathrm{ICU}(n=20)$ & $18(90.0 \%)$ & $13(65.1 \%)$ & & $3(23.1 \%)$ & $6(46.2 \%)$ \\
\hline Total & $58(65.9 \%)$ & $45(51.1 \%)$ & & $7(15.6 \%)$ & $11(24.4 \%)$ \\
\hline
\end{tabular}

*Denotes percentages were calculated on $K$. pneumoniae count and ${ }^{* *}$ denotes percentages were calculated on MHT-positive K. pneumoniae 
in K. pneumoniae isolated in urine and sputum sample, respectively (Additional file 1 : Table $\mathrm{S} 1$ ). Among the carbapenems, meropenem was the most effective. A total of $65.9 \%(58 / 88)$ K. pneumoniae were resistant to at least one of the carbapenem antibiotics used and were labeled as suspected carbapenemase producers (Fig. 1).

\section{Phenotypic confirmation of carbapenemase-producing K. pneumoniae isolates}

Out of 58 suspected carbapenemase producers, 45 (77.6\%) were confirmed as such which constituted $51.1 \%$ $(45 / 88)$ of the total $K$. pneumoniae isolates (Table 2). MHT positivity was higher in males than females. Among the samples, the highest percentage of carbapenemaseproducing $K$. pneumoniae was obtained from the tracheal aspirates $71.4 \%(15 / 21)$, while among the wards, the highest prevalence was in the ICU $65.1 \%(13 / 20)$. The results were, however, statistically insignificant $(p>0.05)$.

\section{PCR results}

Out of 45 carbapenemase-producing isolates, 11 (24.4\%) and $7(15.5 \%)$ were found to be positive for blaNDM-2 and blaOXA- 48 genes, respectively. The prevalence of these genes was higher in males. The highest percentages were found in urine samples $(41.7 \%)$, and the sample of ICU patients, respectively. There was no significant association between the distribution of either gene among the clinical samples and the hospital units (Table 2).

\section{Discussion}

The rapid spread of multidrug-resistant Gram-negative bacteria continues to be one of the most significant challenges to global health [27]. While these bacteria have developed a different mechanism to avert the bactericidal effects of commonly prescribed antibiotics, the increasing prevalence of carbapenemase-producing Gram-negative bacteria is of particular concern [28]. The rapid spread of mobile carbapenemase-containing genes, the limited treatment options, and the high mortality rates for infections associated with carbapenemase-producing isolates make them one of the major public health threats [8].

In this study, $38.8 \%$ of the samples were growth positive, with more than half were Gram-negative bacteria of which $K$. pneumoniae (31.4\%) was the predominant isolate. This was in agreement with previous studies from Nepal [4]. Vibas et al. [29] reported a much higher, while Aryal et al. [30] reported a lower prevalence of $K$. pneumoniae. In this study, the highest percentage of $K$. pneumoniae was found in tracheal aspirates, followed by catheter tips. This was in contrast to that reported by Ferreiria et al. [31]. K. pneumoniae was isolated at the highest rate from the general ward, followed by the OPD and the least from the ICU. This was in contrast tothe study performed by Khan et al. [32]. The variation among the distribution of K. pneumoniae is considerable as the studies used for comparison are from different geographical locations with differing numbers of specimens used. Furthermore, the use of antibiotic therapy among patients, topographical situations, sanitation and the location of the study can also explain the variation in the distribution of $K$. pneumoniae.

Among the 12 different antibiotics used, colistin was $100 \%$ effective against $K$. pneumoniae while $86.3 \%$ isolates were sensitive to tigecycline. Thus, colistin and tigecycline could be the drug of choice for carbapenemresistant K. pneumoniae isolates. Many researchers have also reported high sensitivity against colistin [2, 4, 30]. Ciprofloxacin showing maximum ineffectiveness was in agreement with previous finding in Nepal [19]. MDR is a global issue and a relatively high burden seen in developing countries [27]. Various prevalence of MDR K. pneumoniae have been frequently reported in Nepal [4, 17, 33]. In our study, more than half of isolates were MDR. High prevalence of MDR could be due to the easy availability and blind irrational use of antibiotics without proper culture report and prescription [34, 35].

Out of $88 \mathrm{~K}$. pneumoniae isolates, half were MHT positive. Shanmugan et al. [36] reported a higher prevalence (82.6\%) of MHT-positive K. pneumoniae in India; however, lower prevalence of carbapenemase-producing $\mathrm{K}$. pneumoniae is also reported in India [14], and also in Nepal [37]. In this study, the highest percentage of carbapenemase was observed in tracheal aspirates (74.4\%), followed by catheter tips. On the contrary, Rai et al. [38] reported the highest carbapenem-resistant Klebsiella isolates in urine followed by blood samples. In this study, almost two-thirds of the cases of carbapenemase production were seen in ICU patients and the lowest among OPD patients. Nair et al. also reported a similar trend of carbapenem-resistant isolates from the three different units of the hospital. This higher distribution of carbapenemase producers in the ICU may be related to excessive use of broad-spectrum antibiotics, associated septicemia, and higher comorbidities among ICU patients [39].

The prevalence of OXA- 48 and NDM- 2 among the MHT positive $K$. pneumoniae isolates in our study was $15.6 \%$ and $24.4 \%$, respectively. Manandhar et al. [17] reported a similar prevalence of OXA-48, whereas Solgi et al. [40] reported a much higher prevalence than this study. In this study, the coexistence of both genes was found in $11.1 \%$ of the carbapenemase-producing isolates. Both the genes were predominantly found in isolates from urine. Huang et al. [41] reported the highest percentage of NDM gene in the blood and then followed 
by sputum. Among the wards, the isolation rates of both genes were high in ICU, which was in contrast with the findings of Gonzalez et al. [42]. The variations in the prevalence of the genes might be due to the difference in distribution pattern in different geographical regions and the pattern of antibiotics used.

The rapid increase of antibiotic-resistant genes like the OXA-48 and NDM- 2 poses a significant threat to the modern world [28]. Irrational use of antibiotics, especially in developing countries like Nepal, further escalates the problem. Moreover, the low economy and the lack of well-trained human resources limit the use of genetic detection. In such cases, a relatively easy and inexpensive method like the MHT can be one of the best alternatives for the early detection of the carbapenemase producers [43] although it has several limitations like low specificity and high false positivity [8]. Incorporating of a needy but feasible molecular tests offers a reliable, cost-effective solution for the screening and preventing the dissemination of the MDR carbapenemase producers [9].

\section{Conclusions}

A high prevalence of carbapenemase-producing K. pneumoniae was observed. The prevalence of blaOXA-48 and blaNDM-2 was $15.6 \%$ and $24.4 \%$, respectively. Options for treating infections with carbapenemase-producing K. pneumoniae are limited, and colistin and tigecycline could be the drug of choice. In addition, routine surveillance of MBLs-producing bacteria is necessary to identify appropriate empirical antimicrobial therapy and restrain their spread in a hospital setting.

\section{Limitations of the study}

The study was conducted in only one hospital using a small sample size which may not represent the whole population. Seasonal trend may also affect the result. The study was also limited to a single phenotypic confirmatory test and the detection of only two carbapenemase genes, although many other factors and genes are responsible for carbapenemase activity. Thus, the relationship shown among different factors in this study may not be conclusive. Thus, further studies should be performed in multiple hospitals for a longer period to overcome the present drawbacks.

\section{Abbreviations}

AST: Antimicrobial susceptibility testing; MHT: Modified Hodge test; DNA: Deoxyribonucleic acid; PCR: Polymerase chain reaction; MDR: Multidrugresistant; WHO: World Health Organization; NDM: New Delhi metallo-betalactamase; OXA: Oxacillinase; IRC: Institutional Review Committee; EDTA: Ethylenediamine tetraacetic acid; TAE:Tris-acetate-EDTA.

\section{Supplementary Information}

The online version contains supplementary material available at https://doi. org/10.1186/s41182-021-00368-2.

Additional file 1: Table S1. Samplewise antibiogram of K. Pneumoniae isolates.

\section{Acknowledgements}

We would like to acknowledge the laboratory staff and research participants of ANIAS for their help and support. We are equally grateful to all the colleagues to all the people who directly or indirectly helped in completing this work.

\section{Authors' contributions}

All authors made substantial contributions to conception and design, research work, data analysis; took part in drafting the article or revising it; gave final approval of the version to be published; and agreed to be accountable for all aspects of the work. All authors read and approved the final manuscript.

\section{Funding}

The authors received no financial support for the study, authorship, and publication of this article.

\section{Availability of data and materials}

The datasets generated and analyzed during the current study are available in the supplementary materials repository.

\section{Declarations}

\section{Ethical approval and consent to participate}

The ethical approval was obtained from the Research and Ethical committee, Shi-Gan Health Foundation and NITMPHR, Maharajgunj, Kathmandu, Nepal (IRC Reference No: 04/2071/08/26). Written informed consent was obtained from all the participants above age 16 and from the parent of children under 16 years before sample collection. All methods were carried out following relevant guidelines and regulations.

\section{Consent for publication}

Not applicable.

\section{Competing interests}

The authors declared no conflicts of interest to the research, authorship, and publication of this article.

\section{Author details}

${ }^{1}$ Department of Microbiology, Shi-Gan International College of Science and Technology, Kathmandu, Nepal. ${ }^{2}$ Key Laboratory of Fujian-Taiwan Animal Pathogen Biology, College of Animal Sciences, Fuzhou, China. ${ }^{3}$ Department of Microbiology, Annapurna Research Centre, Kathmandu, Nepal. ${ }^{4}$ Department of Microbiology, Nepal Medical College and Teaching Hospital, Kathmandu, Nepal.

Received: 14 July 2021 Accepted: 10 September 2021 Published online: 26 September 2021

References

1. Hamzan NI, Yean CY, Rahman RA, Hasan H, Rahman ZA. Detection of blaIMP4 and blaNDM1 harboring Klebsiella pneumoniae isolates in a university hospital in Malaysia. Emerg Health Threats J. 2015;8:26011.

2. Mehraj A, Subhas Chandra A, Ganesh R, Kul Raj R, Susil P, Bina B, et al. Prevalence of multidrug-resistance and blaVIM and blaIMP genes among gram-negative clinical isolates in tertiary care hospital, Kathmandu, Nepal. Iranian J Microbiol. 2021;13(3).

3. Parajuli NP, Acharya SP, Mishra SK, Parajuli K, Rijal BP, Pokhrel BM. High burden of antimicrobial resistance among gram negative bacteria 
causing healthcare associated infections in a critical care unit of Nepal. Antimicrob Resist Infect Control. 2017;6(1):67.

4. Shilpakar A, Ansari M, Rai KR, Rai G, Rai SK. Prevalence of multidrug-resistant and extended-spectrum beta-lactamase producing Gram-negative isolates from clinical samples in a tertiary care hospital of Nepal. Trop Med Health. 2021;49(1):23.

5. Koirala S, Khadka S, Sapkota S, Sharma S, Khanal S, Thapa A, et al. Prevalence of CTX-M $\beta$-lactamases producing multidrug resistant Escherichia coli and Klebsiella pneumoniae among patients attending Bir Hospital. Nepal BioMed Res Int. 2021;2021:9958294.

6. Dsouza R, Pinto NA, Hwang I, Cho Y, Yong D, Choi J, et al. Panel strain of Klebsiella pneumoniae for beta-lactam antibiotic evaluation: their phenotypic and genotypic characterization. PeerJ. 2017;5:e2896.

7. Spellberg B, Blaser M, Guidos RJ, Boucher HW, Bradley JS, Eisenstein BI, et al. Combating antimicrobial resistance: policy recommendations to save lives. Clin Infect Dis. 2011;52(Suppl 5):S397-428.

8. Tamma Pranita D, Simner Patricia J, Kraft Colleen S. Phenotypic detection of carbapenemase-producing organisms from clinical isolates. J Clin Microbiol. 2018;56(11):e01140-e1218.

9. Nordmann P, Naas T, Poirel L. Global spread of carbapenemase-producing Enterobacteriaceae. Emerg Infect Dis. 2011;17(10):1791-8.

10. Hall BG, Barlow M. Revised ambler classification of $\beta$-lactamases. J Antimicrob Chemother. 2005;55(6):1050-1.

11. Yong D, Toleman MA, Giske CG, Cho HS, Sundman K, Lee K, et al. Characterization of a new metallo-beta-lactamase gene, bla(NDM-1), and a novel erythromycin esterase gene carried on a unique genetic structure in Klebsiella pneumoniae sequence type 14 from India. Antimicrob Agents Chemother. 2009;53(12):5046-54.

12. Poirel L, Héritier C, Tolün V, Nordmann P. Emergence of oxacillinase-mediated resistance to imipenem in Klebsiella pneumoniae. Antimicrob Agents Chemother. 2004;48(1):15-22.

13. Castanheira M, Deshpande LM, Mathai D, Bell JM, Jones RN, Mendes RE. Early dissemination of NDM-1- and OXA-181-producing Enterobacteriaceae in Indian hospitals: report from the SENTRY Antimicrobial Surveillance Program, 2006-2007. Antimicrob Agents Chemother. 2011;55(3):1274-8.

14. Remya P, Shanthi M, Sekar U. Prevalence and clonal relatedness of NDM and OXA-48-producing Klebsiella pneumoniae in a tertiary care hospital in South India. J Lab Physicians. 2019;11(4):312-6.

15. Karn S, Pant ND, Neupane S, Khatiwada S, Basnyat S, Shrestha B. Prevalence of carbapenem resistant bacterial strains isolated from different clinical samples: study from a tertiary care hospital in Kathmandu, Nepal. J Biomed Sci. 2017;3(1):11-5.

16. Sherchan JB, Tada T, Shrestha S, Uchida H, Hishinuma T, Morioka S, et al. Emergence of clinical isolates of highly carbapenem-resistant Klebsiella pneumoniae co-harboring bla(NDM-5) and bla(OXA-181 or -232) in Nepal. Int J Infect Dis. 2020;92:247-52.

17. Manandhar S, Zellweger RM, Maharjan N, Dongol S, Prajapati KG, Thwaites $\mathrm{G}$, et al. A high prevalence of multi-drug resistant Gram-negative bacilli in a Nepali tertiary care hospital and associated widespread distribution of Extended-Spectrum Beta-Lactamase (ESBL) and carbapenemaseencoding genes. Ann Clin Microbiol Antimicrob. 2020;19(1):48.

18. Gurung S, Kafle S, Dhungel B, Adhikari N, Thapa Shrestha U, Adhikari B, et al. Detection of OXA-48 gene in carbapenem-resistant Escherichia coli and Klebsiella pneumoniae from urine samples. Infect Drug Resist. 2020;13:2311-21.

19. Gautam S, Bhattarai NR, Rai K, Poudyal A, Khanal B. Detection of bla NDM-1 encoding imepenemase among the imipenem-resistant gramnegative bacilli isolated from various clinical samples at a tertiary care hospital of eastern Nepal: a descriptive cross-sectional study. Int J Microbiol. 2020;2020:8861204.

20. Cheesbrough M. District laboratory practice in tropical countries. 2nd ed. Cambridge: Cambridge University Press; 2010.

21. Bergey DHKN, Holt JG. Bergey's manual of systematic bacteriology. Baltimore: Williams \& Wilkins; 1984.

22. CLSI. Performance Standards for Antimicrobial Susceptibility Testing. 25th ed. Approved Standard M100 S25. Wayne: CLSI; 2018.

23. Feliciello I, Chinali G. A modified alkaline lysis method for the preparation of highly purified plasmid DNA from Escherichia Coli. Anal Biochem. 1993;212(2):394-401.
24. Dallenne C, Da Costa A, Decré D, Favier C, Arlet G. Development of a set of multiplex PCR assays for the detection of genes encoding important beta-lactamases in Enterobacteriaceae. J Antimicrob Chemother. 2010;65(3):490-5.

25. Kaase M, Nordmann P, Wichelhaus TA, Gatermann SG, Bonnin RA, Poirel L. NDM-2 carbapenemase in Acinetobacter baumannii from Egypt. J Antimicrob Chemother. 2011;66(6):1260-2.

26. Sambrook J, Russell DW. Standard ethanol precipitation of DNA in microcentrifuge tubes. CSH Protoc. 2006;2006(1).

27. Prestinaci F, Pezzotti P, Pantosti A. Antimicrobial resistance: a global multifaceted phenomenon. Pathog Glob Health. 2015;109(7):309-18.

28. Potter RF, D'Souza AW, Dantas G. The rapid spread of carbapenem-resistant Enterobacteriaceae. Drug Resist Updat. 2016;29:30-46.

29. Vivas R, Dolabella SS, Barbosa AAT, Jain S. Prevalence of Klebsiella pneumoniae carbapenemase - and New Delhi metallo-beta-lactamase-positive K. pneumoniae in Sergipe, Brazil, and combination therapy as a potential treatment option. Rev Soc Bras Med Trop. 2020;53:e20200064.

30. Aryal SC, Upreti MK, Sah AK, Ansari M, Nepal K, Dhungel B, et al. Plasmidmediated AmpC $\beta$-lactamase CITM and DHAM genes among gramnegative clinical isolates. Infect Drug Resist. 2020;13:4249-61.

31. Ferreira RL, da Silva BCM, Rezende GS, Nakamura-Silva R, Pitondo-Silva A, Campanini EB, et al. High prevalence of multidrug-resistant Klebsiella pneumoniae harboring several virulence and $\beta$-lactamase encoding genes in a Brazilian intensive care unit. Front Microbiol. 2019;9(3198).

32. Khan E, Schneiders T, Zafar A, Aziz E, Parekh A, Hasan R. Emergence of CTX-M Group 1-ESBL producing Klebsiella pneumoniae from a tertiary care centre in Karachi, Pakistan. J Infect Dev Ctries. 2010;4(8):472-6.

33. Nepal K, Pant ND, Neupane B, Belbase A, Baidhya R, Shrestha RK, et al. Extended spectrum beta-lactamase and metallo beta-lactamase production among Escherichia coli and Klebsiella pneumoniae isolated from different clinical samples in a tertiary care hospital in Kathmandu. Nepal Ann Clin Microbiol Antimicrob. 2017;16(1):62.

34. Basnyat B, Pokharel P, Dixit S, Giri S. Antibiotic use, its resistance in Nepal and recommendations for action: a situation analysis. J Nepal Health Res Counc. 2015;13(30):102-11.

35. Acharya KP, Wilson RT. Antimicrobial resistance in Nepal. Front Med. 2019;6(105).

36. Shanmugam P, Meenakshisundaram J, Jayaraman P. blaKPC gene detection in clinical isolates of carbapenem resistant Enterobacteriaceae in a Tertiary Care Hospital. J Clin Diagn Res. 2013;7(12):2736-8.

37. Bora A, Sanjana R, Jha BK, Mahaseth SN, Pokharel K. Incidence of metallo-beta-lactamase producing clinical isolates of Escherichia coli and Klebsiella pneumoniae in central Nepal. BMC Res Notes. 2014;7:557.

38. Rai S, Manchanda V, Singh NP, Kaur IR. Zinc-dependent carbapenemases in clinical isolates of family Enterobacteriaceae. Indian J Med Microbiol. 2011;29(3):275-9.

39. Nair PVM. Prevalence of carbapenem resistant Enterobacteriaceae from a tertiary care hospital in Mumbai. India. 2013;3(4):207-10.

40. Solgi H, Nematzadeh S, Giske CG, Badmasti F, Westerlund F, Lin Y-L, et al. Molecular epidemiology of OXA-48 and NDM-1 producing enterobacterales species at a University Hospital in Tehran, Iran, between 2015 and 2016. Front Microbiol. 2020;11(936).

41. Huang X, Cheng X, Sun P, Tang C, Ni F, Liu G. Characteristics of NDM1-producing Klebsiella pneumoniae ST234 and ST1412 isolates spread in a neonatal unit. BMC Microbiol. 2018;18(1):186.

42. López-González L, Viñuela-Prieto JM, Rodriguez-Avial I, Manzano R, Candel FJ. Description of carbapenemase-producing Enterobacteriaceae isolates in a Spanish tertiary hospital. Epidemiological analysis and clinical impact. Rev Esp Quimioter. 2019;32(3):254-62.

43. Pasteran F, Mendez T, Rapoport M, Guerriero L, Corso A. Controlling false-positive results obtained with the Hodge and Masuda assays for detection of class a carbapenemase in species of enterobacteriaceae by incorporating boronic Acid. J Clin Microbiol. 2010;48(4):1323-32.

\section{Publisher's Note}

Springer Nature remains neutral with regard to jurisdictional claims in published maps and institutional affiliations. 